\title{
HACIA UNA EVALUACIÓN DE LA ACTUACIÓN ECONÓMICA Y SOCIAL EN LA TRANSICIÓN CUBANA DE LOS AÑOS NOVENTA ${ }^{1}$
}

\author{
Carmelo Mesa-Lago *
}

\section{INTRODUCCIÓN}

En las tres décadas que transcurren entre 1960 y 1990 Cuba siguió un modelo de planificación central, interceptado por períodos de radicalismo anti-mercado y experimentación con incentivo moral. El ejemplo más reciente de esto último fue el "Proceso de rectificación" aplicado entre 1986 y 1989, que alejó a la economía del mercado (invirtiendo los pequeños avances conseguidos entre 1976 y 1986 bajo un modelo más convencional) con el coste de una recesión. En 1989, Cuba tenía la economía más colectivizada, igualitaria, dependiente del exterior y más subvencionada soviéticamente, de todo el mundo socialista. El movimiento antimercado y la recesión hicieron aún más difícil encontrar una salida a esa situación. El colapso de la URSS y del COMECON fue un soplo devastador para la economía de la isla y, a principios de 1990, forzó un proceso, modesto y zigzagueante, de reformas orientadas al mercado. Este proceso empezó con una apertura hacia la inversión exterior y el turismo, puesto que el gobierno deseaba controlar la reforma dentro de los enclaves extranjeros. En 1993, cuando se demostró que la estrategia no había tenido éxito, el gobierno comenzó de forma recelosa una reforma doméstica. Ha sido un proceso parcial y tímido (comparado con las reformas en China y Vietnam), con la ausencia de un plan bien integrado de etapas coordinados por una secuencia lógica. En su lugar, las medidas se han ido tomando componente a componente, con ocasionales retrocesos y el gobierno a intentado ajustar el control de la reforma recurriendo ha una excesiva regulación. El fortalecimiento del embargo de los Estados Unidos entre 1992 y 1996 ha hecho aún más difícil la reforma. Más que una descripción propiamente dicha de la reforma, disponible en trabajos de autores como Mesa Lago, 1993, 1994a, 1994b; Carranza, Gutiérrez y Monreal 1995; Pérez López, 1994, 1995b; Pastor y Zimbalist 1995), este artículo se propone llenar el vacío que existe en torno a los resultados económicos y sociales de tal reforma entre 1990 y 1997. Esta tarea es difícil puesto que los anuarios estadísticos de Cuba dejaron de ser publicados en 1989 y, hasta 1995, sólo exis- ten cifras ocasionales, dadas por los líderes en sus discursos y estimadas por unos cuantos académicos. Incluso los últimos informes oficiales carecen de datos extensos y de series continuadas.

Este artículo reune, analiza y evalua la fiabilidad de todas las estadísticas sociales y económicas disponibles publicadas en Cuba, así como la información adicional referida a la transición de los años noventa. Se centra para ello en cinco importantes cuestiones: (1) indicadores macroeconómicos (producto nacional, PIB per capita, déficit fiscal, inflación); (2) producción material (azúcar, resto de la agricultura, industria); (3) sector exterior (mercados extranjeros, ayuda, inversión, turismo, dependencia del petróleo y constreñimientos externos); (4) condiciones sociales (desempleo, servicios sociales, desigualdad) y (5) evaluación de las perspectivas económicas y del estado actual de la reforma.

\section{INDICADORES MACROECONÓMICOS: CRECI- MIENTO, PIB PER CAPITA, INFLACIÓN}

\section{(a) Crecimiento del PSB, PIB y PIB per cápita}

Hasta 1989 el Comité de Estadísticas de Cuba (CEE) publicó una serie sobre el Producto Social Global (PSG) basado en el estilo soviético de "sistema de producción material”, que no es comparable con el PIB, que se basa en el sistema occidental de contabilidad nacional (el último anuario estadístico oficial se publicó en 1989 (CEE, 1991) y desde entonces, sólo se han transmitido cifras ocasiona-

University of Pittsburgh

1. Reproducido de "World Development", Volumen 26, Número 5, (Mayo 1998): Carmelo Mesa-Lago: "Assessing 1990 's Economic and Social Performance in the Cuban Transition of the 1990" pp. 857-876, Copyright 1998, con permiso de Elsevier Science.

Un primer borrador de este artículo fue presentado en el Encuentro de la Asociación Económica Americana. El autor agradece los valiosos comentarios realizados por Jorge Pérez López y de tres ponentes anóni mos, así como la ayuda bibliográfica de su asistente de investigación Matthew P. Ligozio. 
les). Unos cuantos académicos cubanos calcularon el PSG entre 1990-1993. La combinación de estos dos conjuntos de datos muestra que el PSG a precios constantes sufrió un descenso acumulado del 45\% entre 1989-1993 (ver la Tabla 1). Una serie del PDG a precios constantes, publicada por la revista cubana más famosa, indicaba un descenso del 48\% para el mismo período (Terrero, 1995). En 1995 el Banco Nacional Cubano desveló diferentes series del PIB a precios constantes que mostraban un descenso de sólo el $35 \%$ para ese período (10 puntos porcentuales menos en el descenso del PSB y 13 puntos menos que el descenso de las series anteriores del PIB). Las series del Banco, sin embargo, revelaban que durante 1986-1989 (durante el "Proceso de Rectificación" antimercado) el PIB cayó un $3.8 \%$, en contraste con una tasa estancada pero positiva del $0.5 \%$ en el GSP (las series del ILO de 1996 sobre el PIB a precios reales mostraban un descenso del $8.7 \%$ en el mismo período). Sea deliberado o no, la reducción de la tasa de crecimiento entre 1986-1989 fue menor que la reducción que se produce de esta tasa entre 19901993. Las estimaciones más recientes, hechas por el ECLAC (1997), muestran un aumento del 2.8\% entre 1986-1989 y un decenso acumulado del $31.6 \%$ entre 1989 1993, el más alto y el más bajo respectivamente, de todos los datos disponibles (Tabla 1). Estos cambios y contradicciones entre las series de datos nos llevan a dudar de la fiabilidad respecto de los datos de crecimiento económico, agravado, ello, por la absoluta ausencia de información en torno al modo en que se calculan las series del PDG, el deflactor que se usa y demás cuestiones. cesta utilizada para calcular el deflactor. Además, con un sector privado en expansión, es necesario saber cuán precisos son los estadistas cubanos al calcular el valor del producto creado en el sector legal no estatal, el autoempleo registrado, las cooperativas de producción, los vendedores de los mercados agrícolas y artesanales, etc, y aún más, el valor de los bienes y servicios generados en el creciente sector ilegal (autoempleo informal o no registrado, mercado negro). Además, es también problemático el uso continuo del año 1981 como base, para el cálculo de las series del PDG a precios constantes, durante más de dos décadas. Esta base fue objeto de críticas durante los ochenta debido a la desaparición del COMECON. Muchos de los productos eran proporcionados a Cuba por la URSS y por otros miembros de esa organización y sus precios estaban enormemente distorsionados; ahora, los precios de esos productos están totalmente fuera de lugar. Por último, pero no menos importante, el peso cubano no se utiliza en el mercado internacional y el gobierno arbitrariamente fija la paridad con el dólar USA (un peso igual a un dólar) pero, las agencias oficiales de intercambio usan, para vender los pesos (los dólares no se venden), la tasa del mercado negro, lo que en 1996 suponía 19 pesos por dólar. En los años noventa, cuando el estado virtualmente poseía y operaba sobre toda la economía y se publicaban muchas estadísticas, existía un acalorado debate respecto a la exactitud de las series de Cuba del SPM y se demostraron importantes imperfecciones al respecto (Mesa-Lago y Pérez López, 1985, 1985b, 1985c). En los noventa, sólo disponiendo de algunas cifras contradictorias que se han

\section{TABLA 1}

$\underline{\text { PSG }} \underline{\text { PIB }}$

\begin{tabular}{|c|c|c|c|c|c|c|c|c|c|c|c|c|}
\hline & & & & & Terret & & & $3 \mathrm{NC}-\mathrm{O}$ & & & ECLA & \\
\hline & Pesos & $\%$ & Indice & Pesos & $\%$ & Indice & Pesos & $\%$ & Indice & Pesos & $\%$ & Index \\
\hline 1985 & 27.070 & 4,6 & 100,0 & & & & 20.369 & & 100,0 & 20.352 & & 100,0 \\
\hline 1986 & 27.390 & 1,2 & 101,2 & 18.480 & & 100,0 & 18.898 & $-6,7$ & 93,3 & 20.385 & 0,2 & 100,2 \\
\hline 1987 & 26.335 & $-3,8$ & 97,3 & 18.177 & $-1,6$ & 98,4 & 18.489 & $-2,7$ & 90,8 & 19.934 & $-2,2$ & 97,9 \\
\hline 1988 & 26.921 & 2,2 & 99,4 & 19.048 & 4,8 & 103,1 & 19.351 & 4,7 & 95,0 & 20.644 & 3,6 & 101,4 \\
\hline 1989 & 27.208 & 1,1 & 100,5 & 19.335 & 1,5 & 104,6 & 19.586 & 1,2 & 96,2 & 20.960 & 1,5 & 103,0 \\
\hline 1990 & 26.228 & $-3,6$ & 96,9 & 18.735 & $-3,1$ & 101,4 & 19.008 & $-3,0$ & 93,3 & 20.349 & $-2,9$ & 100,0 \\
\hline 1991 & 19.934 & $-24,0$ & 73,6 & 14.051 & $-25,0$ & 76,0 & 19.976 & $-10,7$ & 83,3 & 18.415 & $-9,5$ & 90,5 \\
\hline 1992 & 16.944 & $-15,0$ & 62,6 & 12.084 & $-14,0$ & 65,4 & 15.010 & $-11,6$ & 73,7 & 16.591 & $-9,9$ & 81,5 \\
\hline 1993 & 14.964 & $-11,7$ & 55,3 & 10.000 & $-17,0$ & 54,1 & 12.777 & $-14,8$ & 62,7 & 14.332 & $-13,6$ & 70,4 \\
\hline 1994 & & & & & & & 12.868 & 0,7 & 63,2 & 14.421 & 0,6 & 70,8 \\
\hline 1995 & & & & & & & 13.185 & 2,5 & 64,7 & 14.783 & 2,5 & 72,6 \\
\hline 1996 & & & & & & & 14.213 & 7,8 & 69,8 & 15.908 & 7,6 & 78,1 \\
\hline
\end{tabular}

El ministro de economía afirmó en 1996 que el sistema de producción material (SPM), que había sido usado en las economías socialistas de Europa del Este y Cuba, había sido sustituído en las isla por el sistema de contabilidad nacional (SNA), aplicado en casi todos los países del mundo (Rodríguez 1996b). Sin embargo, ninguna publicación cubana muestra ni los métodos seguidos para transformar el MPS en SNA (a lo largo de la Revolución esta conversión se ha revelado para un sólo año: 1974), o la
2. Tres académicos (Pastor y Zimbalist 1995, Tabla 1; Ritter 1995, tabla 2) han estimado: el PIB de Cuba a precios constantes y en dólares americanos, incluyendo el valor de las actividades del sector informal; las series del PIB resultante en dólares durante 1989-1994 fueron entre un $27 \%$ a $66 \%$ más alto que las series en pesos del BNC-ONE. The Economist (1996) utilizó la tasa del crecimiento del PIB entre 1986-1995 para describir la recuperación cubana, mostrando que en 1995, Cuba había casi conseguido el tope de 1988 (lo que en realidad ocurrió en 1985) y que había sido superior al nivel de 1986 (que incorrectamente se dio en PSG). Pero si se hubieran utilizado las cifras absolutas del PIB (que es el procedimiento adecuado para trazar la tendencia), los resultados habrían sido muy diferentes: el PIB de Cuba en 1995 era muy inferior al nivel de 1985 y la recuperación fue extremadamente débil. 
comunicado de forma ocasional y con una economía mixta, la fiabilidad de los datos macroeconómicos cubanos es aún más cuestionable ${ }^{2}$.

La tasa de crecimiento del PIB del Banco Nacional para 1994 era del $0.7 \%$, o lo que es lo mismo, el $0.2 \%$ per cápita (la tasa de crecimiento poblacional de este año fue sólo del $0.5 \%$ debido al brusco éxodo de 35.000 cubanos) y para 1995 , una tasa del $2.5 \%$ o del $1.6 \%$ per capita (Tablas 1 y 2). Estas cifras sugerían que el declive de cuatro años de la economía cubana se había detenido y que se iniciaba una modesta recuperación. El crecimiento neto de 1996 fue en total del 4\% o 5\% per cápita pero, en junio, el ministro de economía anunció una tasa del $7 \%$ para la primera mitad del año (Rodríguez, 1996b; también BNC, 1996). Después de menos de un mes, el vicepresidente del Consejo de Estado, Carlos Lage, situó el crecimiento en el 9.6\%; añadió, sin embargo, que esta alta tasa era el resultado de un aumento en la producción azucarera sólamente computable en el primer semestre, y que la tasa del segundo semestre sería "más pequeña" pero suficiente para completar el crecimiento neto anual del 5\% (Lage, 1996). Un simple cálculo matemático evidencia que para conseguir una tasa anual del $5 \%$, la tasa del segundo semestre sería sólo el $0.4 \%$ o $-0.5 \%$ per cápita. El estancamiento/declive en el segundo semestre puede tener tres explicaciones: (a) el crecimiento tan alto en el primer semestre hacía más difícil conseguir una actuación fuerte durante el segundo (todavía esto no justifica el estancamiento/declive, particularmente a la vista de los informes oficiales de los aumentos de producción en muchos productos del sector no azucarero); (b) el pago de préstamos obtenidos de bancos extranjeros por los cubanos para financiar la cosecha de azúcar redujo su importante capacidad en el segundo semestre (ver sección B-1); y (c) un fuerte aumento de los precios del petróleo en el último cuarto de ese año redujo todavía más la capacidad de importación (ver el punto C-4).

Sorprendentemente, el Presidente Castro anunció en noviembre de 1996, que la tasa de crecimiento del PIB en ese año sería del $7 \%$ y más tarde, en ese mismo mes, el ministro Lage ascendió esta cifra al 8\%. Finalmente, el ministro Rodríguez informó a la Asamblea Nacional el 24 de diciembre, que la tasa de crecimiento para 1996 era del $7.8 \%$, es decir, el $56 \%$ más alta que el pronóstico inicial (Reuters y EFE, 25 de diciembre de 1996) ${ }^{3}$. Si la tasa de la primera mitad del año era del $7 \%$, la tasa de la segunda mitad era un sorprendente $8.6 \%$ (o del 6\% si la del primer semestre era del $9.6 \%$ ). Estas cifras se hicieron más cuestionables debido a un devastador fenómeno natural que ocurrió en el último cuarto del año. Los días 17 y 18 de octubre de 1996, el huracán Lily golpeó a las tres provincias centrales de la isla (que concentran el $46 \%$ de la producción agrícola de la isla) y a la Isla de los Pinos causando daños estimados en 800\$USA (Rodríguez, 1997). Entre las pérdidas en agricultura había: 264.000 toneladas de cítricos, que eran el 46\% de la producción de 1995 (8.000 hectáreas quedaron afectadas), 22.5000 toneladas de café, 22.000 toneladas de plátanos, 523.000 hectaréas de caña de azúcar fueron derribadas o dañadas, 57.000 hectáreas de tubérculos y verduras, 33.000 bancos de semillas de planta de tabaco, y el $80 \%$ de la cosecha de frejol en una provincia. Además, 32 fábricas de azúcar perdieron sus techos o sufrieron otros daños, se dañaron 233 plantas industriales y almacenes, 200 escuelas y 15 hospitales, 275.000 personas fueron evacuadas y acogidas en refugios, 5.000 casas se destruyeron y 80.000 fueron dañadas. No hubo corriente eléctrica durante varios días, por lo que se estropearon miles de toneladas de marisco y tuberculos congelados (Cuba Times, 1996; Miami Herald, del 19 al 23 de octubre de 1996). La necesidad de movilizar a la fuerza de trabajo para recoger todo lo que fuera posible de lo que se produce en el suelo, restablecer las comunicaciones y la corriente, dotar de ayuda a la población sin hogar, supuso un significativo retraso en las actividades que precedieron a la cosecha de azúcar. Las Naciones Unidas, la Comunidad Europea y los exiliados cubanos, proporcionaron ayuda (comida y medicinas), pero era una compensación mínima frente a las fuertes pérdidas sufridas. ¿Cómo pudo Cuba tener un tasa tan alta de crecimiento en el segundo semestre de 1996 a pesar de anteriores informes oficiales negativos y del daño ocasionado por el huracán Lily?

El descenso del PIB per capita entre 1985-1996, en pesos constantes, fue del $36.5 \%$ según el ONE-BNC o del $28 \%$ según el ECLAC (Tabla 2). El PIB per cápita alcanzó en 1985 los 2.006 pesos cubanos o dólares USA, puesto que la tasa oficial de cambio es igual entre las dos monedas. Si utilizamos la tasa de cambio del mercado negro de 6 pesos por dólar, que existía en 1985, entonces el PIB per capita de Cuba de ese año fue de 334\$ USA, parecido al de Haití (World Bank, 1987). En 1996 la media anual de cambio en las casas de cambio oficiales era de 19.2 pesos por dólar (ECLAC, 1997 y Sánchez, 1997), luego el informe oficial del PIB per cápita de 1.274 pesos era igual a 66\$USA, el más bajo del mundo (World Bank, 1996). El gobierno cubano y algunos académicos sostienen acertadamente que la conversión basada en la "tasa informal de mercado" no es exacta porque no tiene en cuenta el valor de los beneficios libres y los subsidios proporcionados a la población (e.g. atención sanitaria, educación, racionamiento de alimentos) que oficialmente se calculan alrededor del $50 \%$ por encima del salario nominal (BNC, 1996). Utilizando el factor de ajuste, el ingreso per cápita sería de $91 \$$ USA.

Otra importante crítica a los cálculos anteriores es que en una economía cerrada, la tasa de cambio informal funciona en un mercado marginal y que esta tasa sería probablemente mejor (menos pesos por dólar) en una economía más abierta, por lo que el uso de esta tasa desfavorable, para convertir el PIB total, subestima el poder adquistivo (purchasing power parity). Las únicas estimaciones recientes disponibles, del ajuste real cubano del PBI per cápita en dólares USA con paridad, están hechas por el UNDP pero

3. La Comisión Económica para América Latina y el Caribe de Naciones Unidas informó que Cuba había crecido un $7 \%$ per cápita en 1996 pero advirtió que esta tasa no se podía asegurar; excluyó la tasa en el sumario analítico anual, pero lo incluyó en el anexo estadístico (ECLAC, 1996b) 
TABLA 2

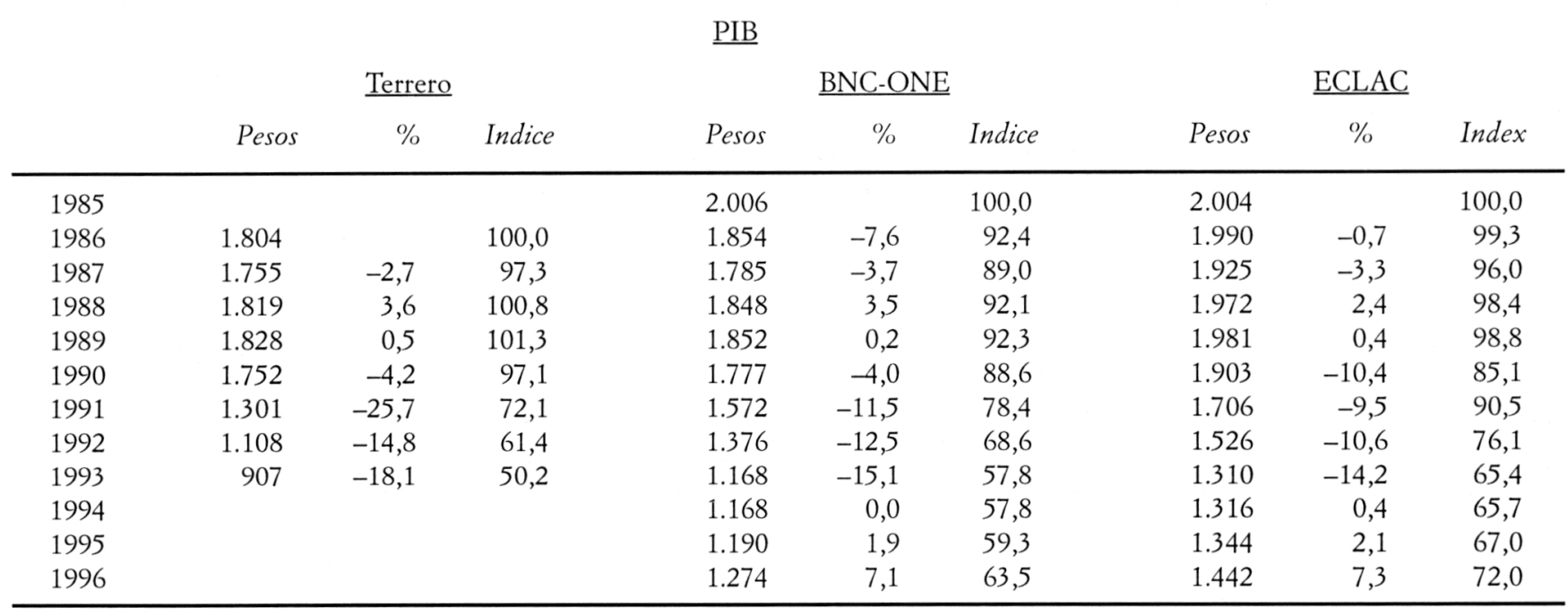

la metodología de estos cáculos no ha sido totalmente desvelada y hay serias dudas sobre su fiabilidad. Para 1993 y 1994, el UNDP calculaba 3.000\$USA (UNDP,1996 y 1997). Durante el primer año la fuente era el Atlas del Banco Mundial (1995), pero en realidad le daba a Cuba un margen de $696 \$$ USA a $2.785 \$$ USA (entre $726 \$$ USA a $2.895 \$$ USA en 1994), el UNDP ajustaba este margen a 3.000\$USA sin explicar cómo. Para 1994 la fuente y la metodología dada por el UNDP fueron las Penn World Tables, como son usadas por Summers y Heston (1991), pero las comparaciones de estos autores se basan en 150 categorías y precios de 400-700 artículos aproximadamente, datos que son virtualmente imposibles de obtener para Cuba. Además las estimaciones son para 1950-1988 cuando Cuba usaba el SPM (PSB) en lugar del SNA (PIB). Por último, pero no menos importante, Cuba no estaba incluída entre esos países para los que el PIB, de Summers y Heston, es calculado con su paridad en dólares. Considerando el indicador del UNDP como valor nominal, en ambos años Cuba ocupó el puesto 27 entre los 33 países de América Latina y el Caribe, por encima de Haití, pero debajo de, entre otros países, Ecuador, Belice, Surinam, Granada, Paraguay, República Dominicana, Perú y Guatemala.

\section{(b) Excedente monetario, déficit presupuestario e inflación}

El último anuario estadístico que publicó datos sobre la inflación de Cuba fue el de 1988 (CEE, 1990) y no se han proporcionado más datos. No obstante, el Banco Nacional y algunos académicos, han publicado datos sobre el superplus monetario, "un balance de la liquidez acumulada", "exceso de liquidez", o de "la liquidez de la población" (e.g la combinación de moneda circulante y cuentas de ahorros que, para simplificar, llamaremos excedente monetario). Desde diciembre de 1989 hasta mayo de 1994, el excedente monetario aumentó casi tres veces y, en 1993, alcanzó aproximadamente el $73 \%$ del PDG a precios corrientes (ver tabla 3). El rápido aumento de emisión monetaria para cubrir el creciente déficit fiscal (de 7.2\% del PDG en 1989 al $33.5 \%$ en 1993-ver Tabla 3) y la fuerte escasez de consumo de bienes y servicios eran las mayores causas de este fenómeno. Puesto que había pocas cosas en las que gastar dinero, una proporción creciente del exceso de liquidez fue a los depósitos bancarios: desde el $49.5 \%$ en 1989 al $63.8 \%$ en 1994 (BNC, 1995). Debido a una necesidad desesperada de una moneda fuerte, en agosto de 1993 el gobierno autorizó a los cubanos la posesión y circulación de dólares, así como los envíos de dólares de los familiares que vivan en el extranjero, y el dólar empezó a sustituir al peso en las transacciones no gubernamentales. El peso fue perdiendo progresivamente su valor (subieron los precios de los bienes y servicios en el mercado negro e informal) y saltó la tasa de cambio del peso por dólares en el mercado negro, de ocho en 1990 a 120 en agosto de 1994. Como resultado de ésto, hubo un grave descenso del poder adquisitivo de la población (Mesa-Lago, 1994b).

Para enfrentarse a los problemas explicados anteriormente, en mayo de 1994, el gobierno empezó el programa de ajuste (programa de desmonetarización lenta) para desviar el dinero de la circulación mediante el aumento de algunos precios, impuestos, y disminuyendo los subsidios a empresas estatales, la inversión y los gastos de vivienda. A finales de 1994, el excedente monetario había sido reducido en un 10\%, en relación a diciembre de 1993 (si atendemos al tope de mayo de 1993 , el recorte fue del $16 \%$ ), pero hubo una deceleración en el programa de ajuste y el declive del excedente monetario era sólo del $6.9 \%$ (ver Tabla 3 ) y en 1996 hubo un aumento del 3.1\% (Tabla 3). El programa se enfrenta a una seria barrera: se necesitan pasos más radicales de ajuste, como la introducción de impuestos sobre los salarios, contribuciones de los trabajadores a la seguridad social, despido de los trabajadores que no se necesitaban en el sector estatal (entre 500.000 y 800.000 puestos de trabajo) y la eliminación de todos los subsidios a las empresas del estado y a los precios (esto último, en realidad, aumentó a precios constantes entre 1995-1996). Pero, el gobierno se muestra receloso con la implementación de estas fuertes medidas debido a sus dañinos efectos 
$\underline{\text { TABLA } 3}$

Masa monetaria

\begin{tabular}{|c|c|c|c|c|c|}
\hline $\begin{array}{l}\text { Millones } \\
\text { de pesos } \\
\text { corrientes }\end{array}$ & $\begin{array}{c}\% \\
\text { de cambio }\end{array}$ & $\begin{array}{l}\% \text { del } \\
P I B \\
\text { actual }\end{array}$ & $\begin{array}{c}\text { Déficit } \\
\text { presupuestario } \\
\text { millones } \\
\text { pesos } \\
\text { corrientes }\end{array}$ & $\begin{array}{l}\text { Déficit } \\
\text { como \% } \\
\text { del PIB } \\
\text { en pesos } \\
\text { corrientes }\end{array}$ & $\begin{array}{c}\text { PIB } \\
\text { millones } \\
\text { pesos } \\
\text { corrientes }\end{array}$ \\
\hline
\end{tabular}

Estimaciones de inflación

\begin{tabular}{ccccc} 
& \multicolumn{4}{c}{ ECLAC } \\
\cline { 2 - 5 } PIB & Deflactor Déficit & PIB en & PIB en Deflactor \\
millones & implicito como & millones & millones implicito \\
pesos & del PIB en pesos & $\%$ del PIB & de pesos del PIB \\
constantes & en tasas depesos & corrientes & constantes $\%$ \\
& de inflación corrientes & &
\end{tabular}

(4)

(5)

(6)

(7)

(8)

(9)

(10)

(11)

(12)

\begin{tabular}{rrrrrrrrr}
-1.403 & 7,2 & 19.486 & 19.586 & & 6,7 & 20.795 & 20.960 & \\
-1.958 & 10,0 & 19.580 & 19.008 & 3,5 & 9,4 & 20.880 & 20.349 & 3,4 \\
-3.765 & 23,1 & 16.299 & 19.976 & $-6,8$ & 21,4 & 17.554 & 18.415 & $-7,1$ \\
-4.869 & 32,7 & 14.890 & 15.010 & 3,3 & 29,7 & 16.382 & 16.591 & 3,6 \\
-5.051 & 33,5 & 15.077 & 12.777 & 19,7 & 30,4 & 16.606 & 14.332 & 17,3 \\
-1.421 & 7,4 & 19.203 & 12.868 & 25,7 & 6,9 & 20.561 & 14.421 & 23,1 \\
-766 & 3,5 & 21.886 & 13.185 & 11,2 & 3,2 & 23.613 & 14.783 & 12,0 \\
-569 & 2,4 & 23.708 & 14.213 & 0,5 & 2,2 & 25.197 & 15.908 & $-0,8$ \\
\hline
\end{tabular}

socio-políticos. Además, el programa ha sido incapaz de corregir una significativa y creciente concentración de los depósitos de ahorros: a mediados de 1995, el 13.6\% de las cuentas tenían el $82.4 \%$ de todos los depósitos, las cifras respectivas para diciembre de 1994 eran $14.1 \%$ y $77.8 \%$ (BNC, 1995; en 1996 el BNC dio cuenta de un continuo aumento de esta concentración). Algunos académicos cubanos sostienen que ese programa de ajuste ha provocados otros efectos adversos: (a) es regresivo porque su peso ha sido desproporcionalmente más fuerte sobre los grupos de bajos impuestos (vía precios), mientras que ha beneficiado a los grupos con altos ingresos (que ganaban grandes beneficios y concentraban el volumen de los depósitos bancarios); (b) es recesivo debido a la contracción de la demanda agregada; (c) es inflacionario y podría conducir a unas mayores presiones inflacionarias, si los depósitos de los bancos son retirados a medida que se abren los nuevos espacios de mercado (el 10\% de estos depósitos fueron retirados en 1995; BNC, 1996); y (d) genera desincentivos para el trabajo y el crecimiento, porque la inversión de los depósitos está severamente restringida. Estos académicos han evaluado varias alternativas al programa actual, como un cambio de moneda con varios grados de confiscación (Gutiérrez, Monreal y Carranza, 1996).

El programa de ajuste ha tenido más éxito en la reducción del déficit fiscal. De acuerdo a las cifras oficiales (Tabla 3) este déficit creció desde los 1.4 billones de pesos en 1989 (7.2\% del PDG) hasta un tope de 5.1 billones de pesos en 1993 (33.5\% del PDG) pero, después de que el programa de ajuste empezara a ser implementado, disminuyó a 1.4 billones de pesos en 1994 (7.4\% del PDG), 776 millones de pesos en 1995 (3.5\%) y 569 millones de pesos en 1996 (2.4\%). El declive del déficit fiscal se ha conseguido a pesar del descenso del $39 \%$ en el ingreso fiscal a pesos constantes entre 1989-1996 y debido a un importante corte del gasto de un $43 \%$, centrado principalmente en inversión, subisidios a las empresas, educación, defensa y seguridad interna (BNC, 1996). El gobierno sostiene que la reducción del excedente monetario ha conducido a: (a)una apreciación del peso cubano desde los 120 por un dólar desde agosto de 1994 a octubre de 1996 (pero esto podría ser, en parte, el resultado de un aumento de los envíos exteriores); (b) el crecimiento económico positivo entre 1994-1996; y (c)un descenso en la inflación entre 1995-1996 (BNC, 1995 y 1996; Lage, 1996; Rodríguez, 1995 y 1996 b).

Sin embargo, el presidente del Banco Nacional, Benigno Regueiro, señaló el 8 de diciembre de 1996, que se haría una nueva emisión ese año de 100 a 200 millones de pesos (la primera desde 1994). Un académico cubano ha estimado una cifra más alta de 434 millones de pesos (Sánchez, 1997), lo que explica el aumento en el excedente monetario de ese año. Hacia el final de 1996, la tasa de cambio del peso se deterioró, desde los 18 a los 20 en las casas de cambio y los 23 en el mercado negro (Nuevo Herald, 19 de diciembre de 1996, pp. 1B, 2B).

El gobierno no ha publicado series del PIB a precios reales que, junto con las ya existentes del PIB a precios constantes, permitan calcular el índice de inflación ${ }^{4}$. La tabla 3 ha rellenado el vacío de la siguiente manera: basado en las cifras absolutas del déficit en pesos reales (columna 4) y sus correspondientes porcentajes de PDG en pesos reales (columna 5), hemos estimado el PIB a precios reales (columna 6), y hemos contrastado el PIB a precios reales y a precios constantes (columna 7 ), con el fin de calcular el deflactor implícito del PIB o el índice de inflación aproximado (columna 8). La tabla muestra que, tras el índice de deflación en 1991, difícil de explicar, el índice de inflación pasó de un 3.3\% en 1992 a un tope del 25.7\% en 1994, y descendió al 11.2\% en 1995 (una estimación preliminar

4. Las series oficiales del deflactor para $1985-1988$ fueron: $-1 \%$ en $1985,-2.8 \%$ en $1986,0.2$ en 1987 y $0.5 \%$ en 1988 ; la media anual para el período fue $-0.7 \%$ (CEE, 1990). Basado en las series de la ILO del PDG a precios reales y las series oficiales a precios constantes (Tabla 1), el autor calculó una tasa anual media del $-1.2 \%$. 
para 1996 indica un corte más allá del 0.5\%). La tasa anual media de inflación entre 1990-1995 era del 9.4\% y probablemente estaba generada por el sector no gubernamental. En este sentido, un índice norteamericano de "precios iguales en el mercado negro" muestra un aumento del $1.762 \%$ entre 1989-1994 (Alonso y Lago, 1995). La hipótesis inflacionaria de los académicos cubanos es apoyada por estos datos hasta 1995, a menos que el gobierno haya exagerado deliberadamente el corte del déficit fiscal o que haya inflado el PIB a precios constantes. Hay una estimación más baja de la inflación, hecha por el ECLAC y que se puede encontrar en la Tabla 3: una media del $8.7 \%$ entre 1990-1995 y una tasa de deflación del $0.8 \%$ proyectada para 1996.

\section{DATOS SOBRE LA PRODUCCIÓN MATERIAL}

Esta sección reúne y analiza todas las estadísticas disponibles de las líneas de producción más importantes (azúcar, el resto de la agricultura, pesca, manufactura y minería), tanto para el consumo doméstico como para las exportaciones. La mayoría de las publicaciones cubanas dan datos sobre producción para los años noventa, basados en cambios en los procentajes anuales, por lo que se hace extremadamente difícil determinar la verdadera actuación al respecto. Algunos de los informes más recientes, sin embargo, publican cifras absolutas para los noventa, pero frecuentemente referidos a años aislados sin conectarlos a los picos de producción conseguidos en los últimos años de los ochenta, dando la impresión de una recuperación más fuerte que la real. (Además, hay informes en los que el valor de algunos bienes y servicios es calculado sin tener en cuenta los costes de producción). Con el fin de corregir esta distorsión, la Tabla 4 compila series estadísticas, todas ellas basadas en datos oficiales, comparando la producción en 1989 (año cumbre en la segunda mitad de los ochenta) con los datos disponibles entre 1992 y 1995.

\section{(a) Producción de azúcar}

La producción azucarera entre 1989-90 era superior a los ocho millones de toneladas y la media para 1981-90 era de 7.7 millones de toneladas anuales. La producción gradualmente descendió a los 7 millones de toneladas en 1992, 4.3 en 1993, 4 en 1994 y 3.3 en 1995 (la más baja en 50 años). La producción aumentó en la cosecha de 1996 a 4.4 millones de toneladas (Lange, 1996) pero aún así, fue la sexta más baja de los últimos cuarenta años. El consumo doméstico en 1995 se estimaba alrededor de las 800.000 toneladas (ECLAC; 1995); asumiendo un nivel de consumo similar para 1996, el aumento del azúcar disponible para su exportación aumentó de las 2.5 millones de toneladas, a 3.6 en 1996, para un beneficio neto de 1.1 millones de toneladas. El precio del azúcar en el mercado mundial era de 13.03 céntimos USA en 1995, pero cayó a una media de 11.73 céntimos USA en 1996 (World Bank, Pink Sheet, 1996). Basado en esos precios el valor de las exportaciones de azúcar en 1995 era de 715 millones de \$USA y 950 millones de \$USA en 1996, para un aumento neto del valor de las exportaciones de 235 millones de \$USA.

Con el fin de aumentar la producción de azúcar en 1996, Cuba tuvo que aceptar sustanciosos préstamos de bancos extranjeros con tasas muy altas de intereses a devolver en un año. Según Fidel Castro (1995) los préstamos eran de 300 millones \$USA y el interés a pagar 50 millones de $\$$ USA, a una tasa de interés del $16.6 \%$. Otras fuentes han dado cifras diferentes que van desde los 130\$USA más 20 millones de \$USA de intereses (Lage, 1996), hasta 200 milones \$USA más 28 millones \$USA ("A Survey..." The Economist, 1996). Basándose en las cifras más altas, de 350 millones de \$USA (préstamo e interés) y el incremento neto del valor de las exportaciones de 235 millones de \$USA, Cuba perdió 115 millones de \$USA en esta empresa. Si utilizamos la deuda total que calcula The Economist, de 228\$USA, hubo entonces una ganancia neta de 7 millones de \$USA. Luego, en lugar del aumento material en la producción de azúcar, contabilizado en el PDG para el primer semestre de 1996, la ganancia neta era o negativa o muy pequeña y el pago de los préstamos debe haber reducido la capacidad importadora de Cuba en el segundo semestre de ese año. La comentada escasez de petróleo en septiembre, reflejaba ese problema (ver 4.4), y el cese de las importaciones podría fortalecer la hipótesis de estancamiento/declive del crecimiento en el segundo semestre.

La previsión inicial para la cosecha de 1997 hablaba de un $20 \%$ por encima de la producción de 1997 , con una producción de más de 5 millones de toneladas, pero la producción real fue de aproximadamente 4.2 millones, debido tanto a causas negativas externas, como a domésticas. A pesar de que dos bancos extranjeros (alemán y español) no renovaron un préstamo combinado de 60 millones de \$USA, Cuba consiguió obtener un préstamo más alto para la cosecha: 339 millones de \$USA al 16\% de interés, pero la ley Helms-Burton estaba oficialmente dañada por un retraso en la obtención de esa financiación que, por su parte, apoyó la recepción de los necesitados ingresos para la cosecha. El huracán Lily causó unas pérdidas de 200.000 toneladas de azúcar en 1997. La gran mayoría de las fábricas cubanas son viejas y sufren frecuentes paradas que interrumpen la trituración de la caña de azúcar; la falta de piezas de recambio provocó un tardío comienzo en muchas fábricas y, en marzo, operaban al $60 \%$ de su capacidad, y sólo el $23 \%$ de todas las fábricas completaron sus previsiones para la cosecha. La caña de azúcar cortada estuvo más de 29 horas en los campos (cuando debería estar recogida en 12 horas para evitar la pérdida de sus propiedades) debido a problemas de transporte: como el no funcionamiento de los equipos, falta de gasolina y piezas de repuesto, el mal estado de las líneas de ferrocarril. La baja productividad laboral fue otra causa, ya que los que cortan la caña de azúcar no tenían guantes ni zapatos, estaban mal alimentados y con falta de incentivos apropiados. Sólo 48 de las UBPCs de la Habana cumplieron su pronóstico, y a nivel nacional tuvieron una muy pobre actuación. Finalmente, había problemas heredados de la cosecha de 1996 que se prolongó excesivamente, lo que pospuso la limpieza y siembra de la siguiente cosecha y se cortó caña 
TABLA 4

Rendimiento de la economía cubana, 1989-1995 (en miles de millones de pesos, a no ser que se especifique de otro modo)

Indicadores

\begin{abstract}
1989
\end{abstract}
1989

Producto físico (miles de tns métricas)

Azucar

Cítricos

Tabaco

Ganado (reses per cápita)

Arroz

Huevos (millones de unidades)

Pescado

Níquel

Aceite

Gas naturas millones $\mathrm{cm}$ cúbicos

Electricidad billones de Kwh

Acero

Cemento

Fertilizantes cientos toneladas

Sector externo (millardos de dólares USA)

Ayuda de la antigua URSS/COMECON

Inversión extranjera desde 1990

Deuda externa en divisas

Tasa de cambio del peso por 1 dolar USA

Total trade transactions

Exportaciones

Importaciones

Balance comercial

Comercio exterior con URSS/Rusia

Aceite importado desde Rusia

Ingreso bruto por turismo (millones pesos)

Ingreso neto por turismo (millones pesos)

Social

Desempleo Abierto (\% de fuerza laboral)

Salarios reales $(1990=100)$

Calorias diarias per capita

Mortalidad infantil por 1000 nacidos

Mortalidad desde los 60 años y más

Tuberculosis por 100.000

Sifilis por 100.000

8.121
$1.015,8$
42
0,49
532
$2.672,6$
192,0
46,6
718
33,6
15,5
314,0
3.759
899

7.030

1992

1993

$\begin{array}{ll}7.030 & 4.380 \\ 787,0 & 644,5\end{array}$

644,5

12,6
0,45

0,46
358

$2.331,2$

177

$1.512,2$

93,5

$32,5 \quad 30,2$

882

1.107

11,5

23, 0

1.100

11,0

90,5

\section{6,0}

\section{6,2}

7

13,5

5,4

8,1

$-2,7$

8,7

7,9

168

101

Estudiantes de Secundaria

Estudiantes Universitarios

Deficit de viviendas

\begin{tabular}{cccccrrr}
7,9 & 25,6 & 35,2 & 33,3 & 31,5 & +346 & +322 & +299 \\
103,8 & 86,2 & 77,2 & 59,5 & 56,1 & -25 & -43 & -46 \\
2.845 & & 1.863 & 1.670 & & -34 & -41 & \\
11,1 & 10,2 & 9,4 & 9,9 & 9,4 & -15 & -11 & -15 \\
48 & & 53 & & & +10 & & \\
6 & 6 & 7 & 12 & & +16 & +100 & \\
82 & 102 & 91 & 105 & & +11 & +28 & \\
1.073 & 820 & 726 & 674 & 703 & -32 & -37 & -34 \\
250 & 223 & 198 & 150 & 128 & -21 & -40 & -49 \\
880 & & 1.100 & & & +25 & & \\
\hline
\end{tabular}

que no estaba madura y que debería haberse dejado para 1997 (Mesa-Lago, 1997; ver 6.1).

\section{(b) Agricultura no azucarera y pesca}

Según el índice de la FAO (basado en 1979-1981), Cuba sufrió un declive en la producción agrícola desde 103.4 en 1989, a 66.6 en 1.994 (FA0, 1.995). Una disminución mayor podría haber ocurrido en 1.995, debido a un descenso de un $20 \%$ en la producción azucarera. Sin embargo, se anunció oficialmente un aumento del $4 \%$ en la agricultura y la pesca (BNC, 1996; Ministerio, 1996). Para el primer semestre de 1996, se anunció un aumento de la

$\begin{array}{llll}1994 & 1995 & 1993 \quad 1994 \quad 1995\end{array}$

$\begin{array}{rrr}1.061 & 1.067 & 1.400 \\ 236 & 218 & 251\end{array}$

\% Cambio respecto a 1989 
(antes de la reforma una pequeña parte de la tierra era cultivada por cooperativas de crédito y de producción, asî como por pequeñas granjas privadas). La mayoría de las granjas del estado, de sectores azucareros y no azucareros, se transformaron en nuevas cooperativas agrícolas de producción(Unidades Básicas de Producción Cooperativa: UBPCs), se dieron en usufructo terrenos individuales y el estado conservó su propiedad (para más detalles de la reforma, ver Deere, 1997). Se esperaba que las UBPCs se auto-mantuvieran, vendiendo al estado el $80 \%$ de sus cosechas a los precios establecidos por el gobierno, por debajo del precio de mercado, y se les permitió vender cualquier excedente en mercados agrícolas libres restablecidos en 1995. La reforma cambió dramáticamente el porcentaje de la distribución agrícola de la tierra por tipo de productor; mientras que en 1989 el $74.3 \%$ estaba en manos de las granjas estatales, el $22.3 \%$ en las viejas cooperativas y el $3.4 \%$ eran granjas privadas. En 1996, estas proporciones eran del $32.8 \%$, el $21.5 \%$ y el $3.4 \%$; además, el $42.3 \%$ de la tierra estaba en manos de las UBPCs (CEE, 1991; "Nonsugarcane...”, 1996; Rodríguez, 1996b). Sin embargo Cuba no siguió el exitoso modelo chino de reforma, donde practicamente toda la tierra del estado se dio a familias y grupos de trabajadores bajo contratos indefinidos. Y donde los granjeros tenían libertad para vender su producción total (sin ninguna cuota obligatoria gestionada por el gobierno) a los precios establecidos por la oferta y la demanda (Mesa-Lago, 1994b). A fines de 1994, el gobierno cubano reconoció que el $41 \%$ de los problemas a los que se enfrentaban las UBPCs, no tenían solución inmediata, el 50\% tenían dificultades que podían solucionarse en un año y, sólo el 9\%, eran rentables e incrementaron su producción (Alfonso, 1995). En 1995, una media del 65\% de todas las UBPCs tenían pérdidas, de las cuales el $75 \%$ producían caña de azúcar y el $25 \%$ restante otros productos agrícolas ("Hay que...", 1996). En el mismo año, los mercados agrícolas libres vendían entre el $25 \%$ y el $30 \%$ de todo lo producido, pero las cooperativas (tanto las viejas como las UBPCs) repartían sólo el 5.1\% de sus ventas totales en esos mercados, mientras que el $11.5 \%$ era distribuído por granjas del estado y el $83.4 \%$ restante por pequeñas granjas privadas que sólo controlaban el $3.4 \%$ de la tierra (BNC, 1995; ONE, 1996). Como resultado del aumento del abastecimiento de la producción en estos mercados, los precios cayeron entre 1994-1996 (ONE, 1996; Deere, 1997). Una evaluación oficial de las UBPCs, hecha en octubre de 1996, concluía que el excesivo protagonismo y control gubernamental sobre ellos, combinado con sus bajos rendimientos, el pobre esfuerzo de la fuerza de trabajo, la falta de incentivos (precios altos pagados al estado por ingresos y bajos precios pagados por el estado), fueran causas de su fracaso a la hora de aumentar la producción y ser rentables (Nuevo Herald, 9 de octubre de 1996, p.1B).

Hay muy pocas cifras absolutas disponibles sobre la producción agrícola no azucarera entre 1989-1995; los datos oficiales son proporcionados en aumentos porcentuales en 1994 y 1995, sobre los años previos (y sólo para ciertos productos) pero no en relación a 1989. La Tabla 4 muestra una serie de cuatro productos importantes entre 1989-1995. Los cítricos son la segunda exportación agrícola más grande, después del azúcar y su producción ha descendido: a pesar del pequeño aumento de 1995, la producción fue un 44\% más baja que en 1990. El tabaco es la tercera exportación y su producción fue un $40 \%$ más baja de la de 1989 , a pesar de un importante aumento en ese año. Las cabezas de ganado per cápita descendieron entre 1989-1994 y entre 19891995 , se produjo un descenso del $46 \%$ en la producción lechera y del $55 \%$ en la producción de ternera (ECLAC, 1997). El arroz es el componente básico de la dieta cubana y el consumo anual era de 500.000 toneladas en 1995; la mayoría del arroz consumido que se importa como producción doméstica cayó un 58\% entre 1989-1995. La producción de huevos era uno de los mayores éxitos de la revolución en materia agrícola, pero su producción cayó un $47 \%$ en el mismo período. En 1996 hubo aumentos en la producción de arroz, cítricos, leche y ternera, pero eran muy pocas cantidades y la producción permaneció por debajo del tope anterior $(-33 \%-35 \%-45 \%$ y $-53 \%$ respectivamente) por el contrario la produccion de huevos y tabaco descendió aún mas (ECLAC 1997 Devtech).

El pescado y el marisco (otra importante exportación) alcanzó las 244.600 toneladas en 1986 (CEE, 1991) y se ha hundido hasta las 192.000 toneladas en 1989; la producción cayó aún más entre 1993-1994, hasta los 94.000, y subió a 106.500 en 1995: un 44\% más bajo que en 1989 y un 56\% más bajo que en 1986 (Tabla 4). Las causas de esta fuerte caída fueron: una reducción del $20 \%$ en la flota pesquera; el $37 \%$ de los barcos restantes eran muy viejos, el $54 \%$ de éstos estan hechos el $24 \%$ de madera, ambos tienen una corta vida y unos altos costes de mantenimiento; el $21 \%$ de los motores venían del campo soviético y no había piezas de recambio; hay una gran escasez de hielo para conservar la pesca de los barcos pesqueros; la grave escasez de petróleo ha reducido las operaciones de la flota; y las limitaciones de zona han forzado a una limitación de la pesca en las aguas tradicionales como Argentina, Chile y Perú (Rodríguez Castellón, 1996).

\section{(c) Manufactura y minería}

Las manufacturas suponían el 27\% del PIB en 1995 (la rama más grande del PIB) y, tras el dramático declive entre 1989-1993, aumentó un 7.6\% en 1994 y un 6.4\% en 1995 (BNC, 1995, 1996; Ministerio, 1996). Pero la Tabla 4 muestra que la producción de los principales productos manufacturareros en 1995 estaba todavía significativamente por debajo de sus niveles de 1989: $-72 \%$ en fertilizantes, $-63 \%$ en cemento, $-36 \%$ en acero y $-20 \%$ en electricidad. Durante 1996, hubo aumentos en los cuatro, pero todavía su producción seguía siendo más baja que en 1989: $-51 \%$, $-54 \%,-27 \%$ y $-13 \%$ respectivamente (ECLAC, 1997). Un economista cubano ha dado cuenta de otro decrecimiento drámatico de la producción en 1989-1995:-98\% en ensamblaje de autobuses en , $-81 \%$ en barras de acero, $-72 \%$ en papel y cartón y $-60 \%$ en cortadores de caña de azúcar. La caída en la producción de los bienes de consumo es aún peor, pero los datos disponibles para 1989-1993, son sólo: $-89 \%$ en jabón, $-66 \%$ en detergente y $-62 \%$ en 
pasta de dientes (Marquetii, 1996a). Otros descensos de los que podemos hablar son, entre 1989-1996, -78\% en textiles, $-54 \%$ en cerveza y $-39 \%$ en puros (ECLAC, 1997).

Las minas suponen sólo el 1\% del GPD y, tras el significativo descenso entre 1989-1994, mostró una importante recuperación en 1995 (BNC, 1995 y 1996). La producción de tres productos mineros se muestra en la Tabla 4. El níquel es la exportación cubana más importante, después del azúcar y su producción cayó un 42\% entre 1989-1994 debido a las siguientes razones: el alto consumo de energía para procesar el citado mineral encontrado en la isla frente al procesamiento más barato de los minerales de sulfuro; la pérdida del rentable mercado soviético (que importaba virtualmente toda la producción cubana, pagando un $50 \%$ más de los precios mundiales del mercado y vendiendoles el petróleo por debajo de los precios de mercado); y la consecuente baja competitividad en el mercado mundial. En 1994 la compañía canadiense Sheritt Inc. empezó a invertir en la modernización y expansión de la producción de níquel, particularmente en la fábrica norteamericana de Moa, tecnológicamente avanzada (Sheritt no invierte en las soviética de Punta Gorda, anticuada tecnológicamente y que consume más energía). Como resultado, la producción de níquel aumentó en 1995, a pesar de ello siguió en un $10 \%$ por debajo de 1989 , y alcanzó el record de 53.700 toneladas en 1996 (La Sociedad, 1995; BNC, 1996; Ministerio, 1996 y ECLAC, 1997). La inversión extranjera condujo a un aumento en la producción de petróleo que alcanzó las 1.470 .000 toneladas métricas en 1995, un salto del $104 \%$ sobre 1989 pero un 58\% sobre 1986; la producción se había calculado que no se incrementaría menos del $2 \%$ en 1996 (BNC, 1996). Tres economistas cubanos señalan, sin embargo, que tal aumento de la producción está contrarrestado por el alto contenido de sulfuro del crudo, lo que dificulta su uso industrial (Carranza, Gutiérrez y Monreal, 1995). La producción de gas natural descendió un $52 \%$ entre $1982-1995$.

\section{EL SECTOR EXTERIOR}

El mayor constreñimiento al que se tuvo que enfrentar la economía de Cuba en la década de los noventa es la reducción drástica del mercado externo, de los créditos, de la ayuda y del abastecimiento de petróleo. En gran medida como resultado del colapso de la zona soviética, pero también como resultado de tres décadas de mala gestión económica y fortalecimiento del embargo americano (MesaLago, 1994b). Los grandes líderes de la economía cubana han reconocido que el problema más complejo al que se enfrentan es el sector exterior, que no ha mejorado a pesar del aumento de la actividad económica (Rodríguez, 1995; Lage, 1996).

\section{(a) Comercio exterior}

En 1987, el 72\% de las transacciones de comercio exterior de Cuba eran con la URSS y $87 \%$ con el COMECON, un 3\% adicional era con China y sólo el 10\% con economías de mercado (CEE, 1991). La desaparición de la URSS y del COMECON, así como el colapso del socialismo en Europa del Este y los problemas confrontados por todos estos países, condujeron a un corte del $96 \%$ del comercio con Rusia y a la práctica inexistencia de comercio con Europa de Este. Rusia ha mantenido un comercio de trueque con Cuba, principalmente azúcar por petróleo pero a precios de mercado, lo que ha reducido no sólo la cantidad sino el valor de las exportaciones a ese país. La mayoría de los países de Europa del Este han condicionado el reinicio del comercio con Cuba al reconocimiento y negociación de la deuda con ellos. Además, la pequeña proprorción de comercio antes de la crisis, que mantenía con las economías de mercado y la escasa diversificación y competitividad de las exportaciones cubanas ha hecho muy difícil para la isla el reintegrarse al mercado mundial. Combinado con estos problemas, está el dramático descenso en la producción y exportación de azúcar (el $75 \%$ de las exportaciones totales entre 1981-1991), del níquel $(7 \%)$, del tabaco $(2 \%)$ y del pescado, marisco y cítricos $(4 \%)$. Como resultado las transacciones totales de Cuba en el comercio descendieron un $76 \%$ en el período, la capacidad de la isla de importar cayó un $65 \%$ y la falta de importaciones clave afectó adversamente a la producción doméstica provocando un círculo vicioso. Las importaciones de maquinaria y de equipo cayeron desde un $37 \%$ sobre el total de las exportaciones en 1990 a un 6\% en 1994 (BNC, 1995) y la planta existente se deterioró rápidamente (muy pocos o ninguna de las fuentes se asignan a la depreciación). A pesar de que el déficit de comercio de mercancías se redujo a la mitad entre 1989-1995, todavía alcanzaba los $1.293 \$$ millones de \$USA en el último año (Tabla 4) y el déficit por cuenta corriente aumentó un 61\% entre 1994-1995. La proyección oficial para 1996 era un aumento del $36 \%$ en las exportaciones y un $11 \%$ en las importaciones, para un descenso del $18 \%$ en el déficit de mercado (BNC, 1996). Pero las cifras reales mostraron un deterioro significativo en 1996: las exportaciones aumentaron un 33\% (hasta los 1.967 millones de \$USA), pero las importaciones también crecieron un 33\% (hasta los 3.695 millones de \$USA), luego el déficit del comercio aumentó un $34 \%$ (hasta 1.728 millones de \$USA), por lo que agravó el problema de la liquidez (Cuba News, 1996; Granma Internet, 1997; ECLAC, 1997). Tanto Lage, como el ministro de Economía Rodríguez, afirmaron que la reducción del déficit del comercio era la tarea obligada más crucial para 1997 (Nuevo Herald, 19 y 25 de diciembre de 1996, pp. 1B, 2B).

\section{(b) Ayuda, deuda e inversión exterior}

En 1989, Cuba recibió aproximadamente 6.000 millones de \$USA en forma de ayuda económica soviética, la mitad como subsidios y la otra mitad en forma de préstamos, pero bajo términos muy generosos (he estimado que Cuba pagó sólo 500 millones de \$USA en intereses de un total de 25.000\$USA recibidos entre 1960-1990; Mesa Lago, 1994a). Además, en 1986, Cuba había recibido 5 billones de \$USA en préstamos de divisa fuerte de las eco- 
nomías de mercado; en ese año el servicio de deuda se suspendió y Cuba ha sido incapaz de renegociar con el Club de París. La deuda de divisa fuerte llegó a ser más del doble, 10.504 millones de \$USA entre 1986-1995, el equivalente al $48 \%$ del PDG a precios reales $(70 \%$ a precios constantes) y siete veces el valor de las exportaciones de 1995, el segundo más alto de la región (BNC, 1996; ECLAC, 1996b, 1997). El bloqueo con los deudores y la crisis económica doméstica han hecho muy difícil y costoso obtener un crédito externo. Con una necesidad desesperada de capital extranjero, a principios de los años noventa, Cuba empezó de facto a liberalizar su ley de 1982 de inversión extranjera que no había producido significativos resultados y una ley de inversión extranjera más liberal que se aprobó en 1995. A pesar de esta apertura, se ha conseguido una modesta acumulación de 2.100 millones de \$USA con la firma de "compromisos de inversión" en 1995, pero se calcula que sólo un tercio de esta suma se ha materializado en forma de dinero fresco (Pérez-López, 1995a; Rodríguez, 1996b; "A survey...", 1996; Tabla 4).

La ejecución en 1996 del Acta Helms-Burton de Estados Unidos, que impone sanciones a los inversores extranjeros en Cuba que hayan "traficado" con propiedades americanas confiscadas, parece haber generado, cuando menos, un efecto intimidatorio que destierra de forma significativa la nueva inversión. Por otro lado, desde agosto de 1993, la cantidad de envíos en moneda fuerte enviados a Cuba por los parientes que viven en el extranjero (principlamente cubano-americanos en Estados Unidos) o turistas en la la isla ha aumentado. El fuerte éxodo de 35.000 cubanos en agosto de 1994, estimulado por el presidente Castro, condujo a Clinton a prohibir esos envíos y los viajes de los parientes desde la isla y a la isla. En octubre de 1995, se produjo una cierta liberalización de esa prohibición, pero se reforzó de nuevo en febrero de 1996 después de que las fuerzas aéreas cubanas derribaran (en aguas internacionales) y mataran a los pilotos de dos aviones estadounidenses Cesna, con base de operaciones en el exilio. Sin embargo, parece que estos envíos (aproximadamente 400 millones de \$USA anuales) siguen entrando en Cuba mediante terceros países.

\section{(c) Turismo extranjero}

El turismo se ha convertido en la segunda fuente más importante de ganancias de moneda fuerte, después del azúcar. El número de turistas extranjeros aumentó de los 270.000 a los 742.000 entre 1989-1995 y a un millón en 1996. Este boom ha estado motivado por la sustanciosa inversión exterior en este área, especialmente de los españoles. Los cubanos obtienen grandes ingresos del turismo (168 millones de \$USA en 1989 y 1.100 millones \$USA en 1995), sin deducir los inputs y otros costes, pero ocasionalmente son ingresos limpios (ingresos atribuíbles a la venta de bienes domésticos o servicios). La proporción de neto/bruto ha ido descendiendo (del 60\% en 1990 al 33\% en 1996) debido a un aumento del coste de los inputs, en su mayoría importados. La tabla 4 muestra que el ingreso neto subió desde los 101 millones de \$USA a los 363 millo- nes \$USA entre 1989-1995, una impresionante multiplicación del 3.5 del beneficio, pero no tanto como la multiplicación del 6.5, declarados como ingreso brutos (los ingresos brutos y netos calculados para 1996 son 1.380 \$USA y 439 millones de \$USA resperctivamente). Además las previsiones iniciales establecían, para 1995, 1.5 millones de turistas y 2.000 millones de \$USA de ingresos brutos; mientras que la realidad redujo a la mitad estos objetivos, pospuestos ahora hasta el año 2000. Finalmente, el porcentaje de ocupación de las 26.900 plazas hoteleras en 1996 es muy bajo, a pesar de haberse elevado desde el $43 \%$ al $55.9 \%$ entre 1991-1996, y la media de días de estancia subió de los 8.7 a los 9.6 días entre 1991-1993, pero descendió a los 7.3 en 1996 (CCE, 1992; BNC, 1996; CEA, 1996a; ECLAC, 1996a y 1997).

\section{(d) Dependencia del petróleo}

En 1987 Cuba recibió 13.5 millones de toneladas de petróleo y de productos derivados de éste de la URSS, incluyendo casi 8 millones de toneladas de crudo, que supusieron el $89.3 \%$ del abastecimiento total; el $10.2 \%$ restante fue completado por producción doméstica y el otro $0.5 \%$ por importaciones de otros países. En 1994, el suministro total de petróleo había descendido hasta aproximadamente los 5 millones de toneladas, un 1.3 de esta cantidad provenía de la producción doméstica, otro 1.6 era importado de Rusia (a cambio de azúcar, ambos a precios de mercado mundial), y el resto importado de otros paises (Mesa-Lago, 1994a, 1994b). La escasez de gasolina es uno de los grandes constreñimientos para la recuperación de la economía cubana, y las relaciones de mercado de Rusia con la isla se han torcido por los últimos incumplimientos de la cuota de exportación de azúcar acordada anualmente para el cambio por petróleo ruso. La parte de importación del petróleo sobre el total de las importaciones cubanas aumentó del $27 \%$ en 1990 al $39 \%$ en 1994 y al $41 \%$ en 1995 (BNC, 1995; Rodríguez, 1995).

La escasez de gasolina se agravó en el último cuarto de 1996 debido a un salto en los precios del crudo en el mercado mundial (el barril de petróleo pasó de los 17\$USA a los 23\$USA entre noviembre de 1995 y noviembre de 1996, la media anual de precios era de 16.11 \$USA en 1995 y 18.54 \$USA en 1996), y a un aumento del $24 \%$ en los precios de la gasolina diésel, que empujaron la parte de importaciones de gasolina al $42 \%$ en ese año (el coste de las importaciones de petróleo de 1.200 millones en 1996). Además, hubo una seria pelea con Rusia sobre el reparto y precio del azúcar cubano, el abastecimiento de petróleo se suspendió y, en septiembre, Cuba puso un pleito contra la empresa rusa de petróleo. El 23 de septiembre, hubo apagones no anunciados en la Habana, no hubo gas natural disponible ese día, y el gobierno anunció una suspensión del queroseno para el resto del año; hubo otros apagones durante el resto de 1996. El plan para 1997 ordenaba un corte en el abastecimiento y el consumo; el ministro Rodríguez avisó de que la economía no podía crecer si las importaciones de gasolina aumentaban de manera desproporcionada, y el sindicato de papel pidió un ahorro de 
energía y un aumento de las tarifas de la electricidad a las empresas estatales. Sin embargo, en febrero de 1997, la pelea cubana con Rusia se había solucionado y los repartos de petróleo se reanudaron, facilitando la situación de alguna manera, en la primera mitad de ese año. Además, los precios del mercado mundial de petrólo descendieron ligeramente en 1997. Sin embargo, el descenso en la producción de azúcar en 1997, puede crear problemas de nuevo (Juventud Rebelde, 15 de Septiembre de 1996; Noticiero Nacional de TV, 19 de septiembre de 1996; Nuevo Herald, 25 y 28 de septiembre de 1996, pp. 8A y 1B, 19 de diciembre de 1996, p. 1B, 2B; Godínez, 1997).

\section{(e) La restricción exterior}

La Tabla 5 combina todos los datos disponibles, que se han expuesto en esta sección, para estimar de forma general la recuperación de una divisa fuerte entre 1989 1995. Antes de las crisis, en 1989, Cuba recibía 11.500 millones de \$USA de las exportaciones, de la ayuda externa y del turismo. Esta suma descendió hasta 1.800 millones de \$USA en 1993 (incluyendo la inversión exterior y los envíos) y, tras un modesto aumento, alcanzó los 2.800 \$USA en 1995 , el $76 \%$ menos que en 1989 . Se podría preguntar en torno a la conversión de los rublos rusos en dólares USA en 1989 utilizando la tasa de intercambio de ese momento pero, se puede señalar que, a pesar de la tasa de cambio utilizada, Cuba logró el poder de importar muchos productos de la URSS que ahora faltan. Otra cuestión podría ser la calidad y precios reales de los bienes soviéticos importados. Admitiendo que la cali$\mathrm{dad} /$ precio de las maquinaria y manufactura de la URSS no podía competir con aquellas desarrolladas en economías de mercado, incluso Cuba estaba abastecida con más petróleo del que consumía (el plus era vendido a precios de mercado mundial) y la maquinaria soviética y el equipamiento hicieron posible la expansión industrial, los aumentos en la producción de azúcar, etc.

\section{Tabla 5}

Estimaciones de los ingresos de divisas de Cuba: 1989-95 (en miles de millones de dólares USA)

\begin{tabular}{lrrrrr}
\hline Revenue sources & 1989 & 1992 & 1993 & 1994 & 1995 \\
\hline Exportaciones & 5,4 & 1,8 & 1,1 & 1,3 & 1,5 \\
Turismo (neto) & 0,1 & 0,2 & 0,2 & 0,3 & 0,4 \\
Envíos extranjeros & 0,0 & 0,1 & 0,2 & 0,4 & 0,4 \\
Ayuda & & & & & \\
externa/inversiones & 6,0 & 0,4 & 0,4 & 0,4 & 0,4 \\
Total & 11,5 & 2,3 & 1,8 & 2,3 & 2,8 \\
\% Reducción/1989 & 0 & -80 & -84 & -80 & -76 \\
\hline
\end{tabular}

\section{CONDICIONES SOCIALES}

Bajo la Revolución, Cuba consiguó niveles de pleno empleo, asistencia sanitaria, educación, pensiones e igualdad en la distribución (pero no en viviendas), que se situaron en la cima de los del mundo socialista y América
Latina. La crisis económica de los años noventa y el ajuste, han creado un nivel significativo de desempleo, ha dañado los servicios sociales (que eran prácticamente universales y gratuitos) y ha generado una considerable desigualdad (Mesa-Lago 1994b). Esta sección evalúa los nuevos datos sociales disponibles.

\section{(a) Desempleo}

La crisis condujo, entre muchos otros hechos, al cierre de alrededor del $70 \%$ de la planta industrial, al cierre del más grande complejo niquelero, del $90 \%$ de los transportes en La Habana y otras ciudades. Al mismo tiempo miles de tropas cubanas estacionadas en África y en otros lugares, así como los "trabajadores internacionales" (físicos, maestros, enfermeras, trabajadores de la construcción) que tenían contratos de trabajo en la URSS y en los países de la Europa del Este volvieron a Cuba. Mientras que la fuerza de trabajo aumentaba, la demanda disminuía y el desemplo fue el resultado. En los noventa, Cuba introdujo un programa de "racionalización", para redistribuir a los trabajadores del estado que sobraban, combinado con subsidios de desempleo. En 1992, el autor calcula, que entre el 10\% y el $18 \%$ de la fuerza de trabajo estaba desempleada o afectada por el programa de reubicación (Mesa-Lago, 1993). Según las estimaciones del ECLAC, que se reproducen en la Tabla 4, la tasa de desempleo, combinada con los trabajadores sobrantes que reciben subsidio de desempleo, era de $25.6 \%$ en 1992 y ascendió hasta $35.2 \%$ en 1993 , decendendiendo a $31.5 \%$ en 1995 .

En 1995 el gobierno afirmó que el 8\% de la fuerza de trabajo estaba desempleada (7'9\% de acuerdo al ECLAC 1997) pero, anunció que las reformas económicas requerían la eliminación de los subsidios a las empresas públicas que no eran rentables y el consecuente despido de 500.000 a 800.000 trabajadores innecesarios dentro del sector estatal (Lage 1996). Estos despidos incrementaron la tasa de desempleo entre 12 y 19 puntos porcentuales más respecto de la fuerza de trabajo (esto último fue estimado como 4.131.000 por el ECLAC, 1997), para una tasa de desempleo del 20\% al 27\% (Otro estima que: el 20\% tras los despidos, por Radio Rebelde realizado por la CEA, 1996a, y $26.7 \%$ antes de los despidos por el Instituto Cubano de Economistas Independientes, 1995). Según el vicepresidente Raúl Castro (1996): "Cientos de miles de trabajadores estatales están desempleados o su trabajo ha sido reducido, y ha habido crecimiento del desempleo entre docenas de miles de gente joven que acabaron sus carreras y no pueden encontrar empleo. Esto ha tenido un traumático efecto sobre la juventud y miles de ellos han abandonado el país”.

Para proporcionar empleo a los trabajadores del estado que no se necesitaban o que habían sido desplazados, el gobierno reautorizó el autoempleo en 1993 (se permitió en 1980, se criticó en 1982 y se restringió hasta 1993). A pesar de algún retroceso (e.g. prohibición de pequeños restaurantes autorizados y conductores de taxis privados que fueron reautorizados más tarde), el número de ocupaciones de autoempleo legales se ha ido expandiendo gradualmente hasta 160 en 1996. Aún se prohibe a los graduados univer- 
sitarios y a los profesionales desarrollar sus ocupaciones como trabajadores autoempleados (e.g. un físico no puede practicar la medicina pero puede ser un fontanero), mientras los ejecutivos del gobierno y los altos cuadros no pueden trabajar en ninguna actividad de autoempleo (para un estudio detallado, ver Pérez-López, 1995b). Además, el gobierno ha impuesto reglas burocráticas (para el registro, inspección, etc.), tasas de licencia, fuertes impuestos al autoempleo, así como duras sanciones a los que violen la ley y se enriquezcan ilegalmente (en 1995, 4.8 millones de pesos habías sido confiscados y otros 10.8 millones congelados supuestamente debido al enriquecimiento ilegal). En junio de 1996 había 208.5000 autoempleados registrados (el $4.5 \%$ de la fuerza de trabajo o el $4.9 \%$ del total de empleo), un número considerablemente más bajo que los 300.000 proyectados para ese año e insuficiente para absorber a todos los trabajadores estatales no necesitados. Además, sólo el $29 \%$ de los autoempleados eran antes desempleados y sólo otro $29 \%$ estaba antes empleado, el $24 \%$ de los trabajadores eran jubilados y el otro $18 \%$ amas de casa (Rodríguez, 1996b; CEA, 1996a). Un gran número de autoempleados no están registrados y desarrollan su trabajo ilegalmente; los cálculos van desde los 190.000 (Alfonso, 1996) a los 625.000 y 2.1 millones (CEA, 1996a). Además, el $12 \%$ de la fuerza de trabajo civil está formada por trabajadores a tiempo parcial ("Uso...", 1996). Los puestos de trabajo creados por inversión externa, incluído el turismo, fueron sólo 55.000 en 1995 (Fernández, 1996). Los trabajadores de UBPCs no se añaden al empleo total porque previamente habían estado empleados en fábricas del estado. Y Raúl Castro (1996) ha destacado que los trabajadores estatales no necesitados, no serán absorbidos por la agricultura porque este sector también debe aumentar su productividad.

El presidente Castro ha resistido la presión a autorizar la propiedad de los pequeños negocios en industria, comercio, transporte y servicios no incluídos en las ocupaciones autorizadas de autoempleo. Hubo un borrador legal circulando desde 1995 que autorizaba a los ciudadanos cubanos la posesión de pequeños negocios, y el rumor de que este borrador sería aprobado en 1996. Sin embargo, en abril de 1997, Lage dijo que esa medida tendría que ser pospuesta y no hubo ninguna alusión a ésta en el Congreso del Partido que se celebró en octubre de 1997.

En resumen, el número total de trabajos legales añadidos entre 1993-1996, mediante autoempleo e inversión externa, fue de 263.500 , entre la mitad y el tercio del número de los trabajadores que habían sido despedidos. Uno de los anteriores ministros de economía español y consejero del gobierno cubano, ha avisado de que incluso si las restricciones al autoempleo se eliminan y el número registrado se duplica, estos trabajos serían todavía insuficientes, de ahí la necesidad de autorizar a los ciudadanos cubanos a poseer pequeños y medianos negocios (Solchaga, 1995). La reticencia del gobierno a avanzar en la reforma llevó a una posposición de los despidos masivos: sólo 17.000 trabajadores del estado fueron "racionados" en 1995. Tras establecer fuertes impuestos al autoempleo a finales de 1996, el número de los registrados descendió desde los 208.500 a los 180.000 , al contrario del aumento oficial proyectado del $67 \%$ para ese año, y más adelante, en marzo de 1997 , descendió a los 171.861 (BNC, 1996; Nuevo Herald, diciembre de 1996, pp. 1B, 2B y 27 de marzo de 1997, p. 7-A).

\section{(b) Salud, educación y vivienda}

La falta de 300 medicinas, vacunas, material quirúrgico y recambios del equipo, combinado con la reducción del consumo de alimentos, han conducido al deterioro de los niveles de salud en Cuba. El gobierno sostiene que ningún hospital ha sido cerrado y que la mortalidad infantil ha seguido descendiendo: desde 11'1 por cada 1.000 en 1989 a 9'4 por 1000 en 1995 (Tabla 4). Incluso si estos datos fueran exactos, la Tabla 4 muestra el deterioro en muchos de los otros indicadores de salud: el consumo diario de calorías por persona descendió desde 2.845 hasta 1.610 entre 1989 y 1994 (muy por debajo del mínimo que establece la Organización Mundial para la Salud); las tasas de mortalidad a partir de los 60 años ascendieron desde 48 a 63 entre 1989 y 1993; los casos de tuberculosis por cada 100.000 habitantes se duplicaron desde 6 a 12; y los casos de sífilis aumentaron de 82 a 105 . En la primera mitad de 1993, una epidemia de neuritis óptica, causada por malnutrición y deficiencia vitamínica, afectó a 45.584 pesonas (Gay et al. 1994).

En materia de educación, hubo una gran escasez de papel, lápices, bolígrafos, libros y demás. El número de estudiantes de secundaria aumentó en 1980 y alcanzó los 1.073.000 en 1989, pero descendió a 703.000 en 1995. El descenso de la matricula universitaria fue aún más dramático: de 250.000 a 128.00 entre 1989 y 1994. La falta de oportunidades de empleo, señalado por R. Castro, ha supuesto la desincentivación para cursar estudios superiores (ver la sección 3).

La vivienda ha sido el único servicio social seriamente descuidado por la Revolución. El número total de casas construídas aumentó de 60.576 en 1980 a 74.437 en 1985 , pero descendió a 69.107 en 1987 (la población cubana sobrepasaba los 11 millones de habitantes en 1996). En lugar del "boom de la vivienda", en la primera mitad de los ochenta, el déficit de viviendas alcanzó los 880.000 y probablemente ha superado el millón en 1989 (Mesa-Lago, 1993 y 1994a). Según Raúl Castro (1996) la escasez de viviendas, que ya era muy grande anteriormente a la crisis, se ha empeorado en los años noventa porque toda la inversión se ha frenado abruptamente (la tabla 4 sitúa el déficit de viviendas en 1993 en 1.1 millones de unidades).

\section{(c) Desigualdad}

A finales de los ochenta Cuba tenía una de las distribuciones de ingresos más igualitarias del mundo: la diferencia de salarios era de 5 sobre 1 . Las reformas han generado desigualdades significativas en Cuba. La media real mensual de salario descendió un 46\% entre 1989 y 1995 debido al aumento de los precios de los bienes consumibles fuera del racionamiento (Tabla 4; basada en ECLAC 1997). En 1995, las cuotas de racionamiento cubrían las necesidades míni- 
mas alimenticias para la mitad de un mes y la otra mitad tenía que ser completada con dólares o significativos ingresos en pesos, para comprar en las tiendas de dólares del estado, mercados agrícolas y/o en el mercado negro. La media mensual de salario en 1995 era 193 pesos, equivalente a $6 \$$ USA en el mercado negro del cambio, o 6 "pesos convertibles", sólo válidos en las tiendas de dólares del estado, las agencias de cambio del gobierno (la tasa media anual de intercambio usada era 32.1 por uno, proporcionada por ECLAC,1997 y Sánchez, 1997). Con ese salario completo compraría un cuarto de libra de ternera o de café, o dos libras de cerdo o un litro de petróleo en una tienda de dólares del estado (parte de ese salario, por supuesto, tenía que gastarse en bienes racionados, transporte, etc.).

Tres economistas cubanos han estimado que, en 1994, el ingreso más bajo que se conseguía en el sector informal superaba en un día el salario medio mensual del sector estatal (Carranza, Gutiérrez y Monreal, 1995). La Tabla 6 intenta extender esta afirmación mediante medidas un tanto rudas de las desigualdades de ingreso según ocupación y las compara con el salario medio estatal. Los que ganan una pequeña pensión o los empleados a los que se paga con el salario mínimo y no pertenecen al sector de autoempleo son los que están en la peor situación; aquellos empleados por el gobierno y a los que se les prohibe desarrollar formas de autoempleo han visto reducido drásticamente su poder adquisitivo. Según la tabla, en 1995 el propietario de un pequeño restaurante ganaba entre 414 y 828 veces más que la media de salario mensual, o entre 228 y 400 veces lo que cobraba un cirujano, un ingeniero o un profesor de univerisdad. Otras personas que tenían altos ingresos eran los que cedían sus casa a turistas, las prostitutas, los agricultores privados, los conductores autónomos de taxis y los camareros en hoteles de turistas. Debería señalarse que algunos de los que tenían ingresos más bajos tenían actividades paralelas, pagadas en dólares, ello supone que las diferencias no eran tan pronunciadas como las que se muestran en la tabla. Hemos señalado ya (sección 2 2) que el $13.4 \%$ de todos los que tenían cuentas bancarias en 1995 controlaban el $82 \%$ de los depósitos bancarios. Finalmente hay que señalar que los envíos extranjeros llegan principalmente a los blancos, porque sólo un 3\% de los exilidados cubanos son negros, sin embargo aproximadamente la mitad de la población cubana es negara o mulata (Mesa-Lago, 1994b).

\section{EVALUACIÓN DE LAS PERSPECTIVAS ECONÓMICAS Y DEL STATUS DE LA REFORMA}

Esta sección evalúa en primer lugar las perspectivas económicas de Cuba en el futuro inmediato, luego analiza la marcha de la reforma económica atendiendo a varios indicadores (progreso, estancamiento o retroceso) y explora brevemente las potenciales políticas alternativas.

\section{(a) Las perspectivas económicas para el futuro inmediato}

A finales de 1996 Lage y Rodríguez coincidían en que el crecimiento del PIB en 1997 sería considerablemente más pequeño que en 1996; Rodríguez lo estimaba entre el 4\% y el 5\%. Advirtieron que 1997 sería un año difícil y complejo con una continua "tensión financiera severa" para obtener un crédito a corto y medio plazo. "La austeridad y la disciplina" serían necesarias y, tanto la deuda interna como el déficit externo de mercado, tendría que ser reducido. La tasa de crecimiento para 1997 sería modesta por diferentes motivos: (a) el daño producido por el huracán Lily (800 millones de \$USA), a pesar de que en realidad ocurrió en 1996 hubo repercusiones en 1997, como retrasos en el trabajo previo a la cosecha; (b) el Acta Helms-Burton que supuso 200 millones de \$USA en finaciación exterior; (c)baja eficiencia de las UBPCs en la caña

TABLA 6

Desigualdades de los ingresos por ocupación en Cuba: 1995 (ingreso mensual)

\begin{tabular}{|c|c|c|c|}
\hline Ocupación & Pesos & Dólares USA & $\begin{array}{l}\text { Porcentaje de los } \\
\text { salarios medios }\end{array}$ \\
\hline Salario medio & 193 & 6 & 1,0 \\
\hline Salario mínimo & 100 & 3 & 0,5 \\
\hline Pensión mínima & 90 & 3 & 0,5 \\
\hline Profesor & $250-280$ & $8-9$ & $1,3-1,4$ \\
\hline Suplemento para pescadores por captura extra & 300 & 9 & 1,5 \\
\hline Cirujano, ingeniero superior, profesor de universidad & $350-400$ & $11-12$ & $1,8-2,1$ \\
\hline Suplemento en dólares a ciertos trabajadores & $600-900$ & $19-28$ & $3,1-4,7$ \\
\hline Camarero en hotel de turistas (propinas) & 3.000 & 93 & 15,5 \\
\hline Peluquero (autoempleado) & 3.000 & 93 & 15,5 \\
\hline Conductor de caballos & $3.000-4.000$ & $93-125$ & $15,5-20,7$ \\
\hline Taxista con turistas & $3.000-15.000$ & $100-467$ & $15,5-77,7$ \\
\hline Granjero privado & $6.000-10.000$ & $187-311$ & $31,1-51,8$ \\
\hline Pariente recibiendo ayuda & $9.000-30.000$ & $280-934$ & $46,6-155,4$ \\
\hline Ingreso en dólares de prostitutas & 12.000 & 373 & 62,2 \\
\hline Alquiler de casas para turistas & $15.000-21.000$ & $467-654$ & $77,7-108,8$ \\
\hline Propietario de pequeño restaurante & $80.000-160.000$ & $2.500-5.000$ & $414,5-829,0$ \\
\hline
\end{tabular}


de azúcar; y (d) continuos bajos precios en el azúcar y altos precios del petróleo en el mercado mundial. Con el fin de reducir la deuda doméstica y el déficit del mercado exterior, a pesar de las fuertes medidas que se anunciaron: (a) todas las empresas que operaban en dólares debían ser rentables, aquellas con más de un año de déficit serían cerradas; (b) las licencias para las empresas que operaran con divisa fuerte serían rechazadas o retiradas (200 sufrieron este destino afinales de 1996) y (c)la inversión debían ser "racionalizada" y las empresas deben intentar conseguir créditos exteriores. Estas medidas de ajuste se esperaba que tuvieran un impacto adverso sobre el crecimiento en 1997 (Nuevo Herald, 4-19 de diciembre de 1996, pp. 2B y 1B, 2B; Granma en Diciembre de 1996).

La caída de la cosecha de azúcar de 1997 agravó la miseria económica de ese año. No sólo se produjeron 350.000 toneladas menos en 1997 frente a 1996, sino que la producción real de azúcar fue de un millón de toneladas menos de lo proyectado para 1997, un aumento que hubiera sido necesario para devolver el préstamo exterior. Los precios del azúcar descendieron aún más, de los 11.3 céntimos USA por libra en 1996, a los 10.97 entre enero y septiembre de 1997, y el valor estimado de las exportaciones de azúcar fue de 870 millones de $\$$ USA menos que en 1996. El coste del préstamo, más el interés, para la cosecha de 1997 fue de aproximadamente 383 millones de \$USA, por lo que se hizo aún más difícil que en 1996 pagar ese préstamo. Los precios del petróleo descendieron sólo ligeramente en este mismo período, de los 18.54\$USA a los 18.17\$USA por barril, proporcionando con ello un escaso alivio a la reducción de los costes de producción y al valor de la importación (World Bank, Pink Sheet, 1996-1997). Según Lage (1997), Cuba tiene que pagar 1.40\$USA por cada dólar prestado. El descenso de la producción de azúcar en 1997, tuvo un impacto negativo sobre el crecimiento e hizo mucho más difícil devolver el préstamo (que era más alto y cosotoso entonces, en 1996) y redujo el potencial crédito exterior para la cosecha de 1998.

La crisis de liquidez supuso mayores restricciones al crédito deméstico y el retroceso de algunos de los progresos previamente conseguidos durante la estabilización. Entre los ya mencionados, un aumento de la emisión monetaria en 434 millones de pesos en 1996, tras un descenso entre 1994-1995, y el principio de retiradas completas de los depósitos bancarios entre 1995-1996 (mientras que habían estado subiendo mucho anteriormente). Además, Lage (1997) habló de altos aumentos en ventas al por mayor y al por menor en 1997 (que probablemente condujeron a un aumento de la inflación tras dos años de descenso), el mal tiempo en el invierno de 1997, una importante plaga del insecto Trip Palmi. Esto último causó un daño severo en 15 cosechas, (e.g. 20.000 toneladas de verduras y tubérculos se perdieron, y un fuerte descenso en el rendimiento de las tres provincias del oeste; el insecto era inmune a los insecticidas químicos y al control biológico (Juventud Rebelde, 26 de octubre de 1997). Las únicas perspectivas positivas son el turismo y el níquel.

El crecimiento del PIB para 1997 fue calculado por Lage (1997) como de más de un 2\% (aproximadamente un
$1.4 \%$ per cápita), entre los 2 y 3 puntos porcentuales menos del previsto inicialmente. El crecimiento de la media anual oficial del PDG per cápita entre 1995-1997 fue del 3.6\%; incluso a ese ritmo llevaría 12 años recuperar el nivel del PDG per cápita de 1985, lo que era escaso para empezar. Y las perspectivas para 1998 no son buenas porque se redujo el acceso a los créditos exteriores, se ralentizó la inversión extranjera, los problemas en la agricultura (incluyendo la plaga, la falta de inputs, la ineficiencia de las UBPC), el aumento de las presiones inflacionarias. En octubre de 1997, Lage señaló que "la recuperación económica es irreversible", pero advirtió de que "habría interrupciones ocasionales" y dijo que era imposible establecer previsiones cuantitativas para 1998. A la vista de estos problemas, hubiera parecido lógico que el gobierno diera otro impulso a la reforma orientada al mercado pero, a finales de 1997, esto aún no ha ocurrido.

\section{b) ¿Está la reforma económica progresando, estancada o retrocediendo?}

Los indicadores del progreso de la reforma económica desde finales de 1995 hasta el final de 1997 eran: (a) la aprobación, tras varios retrasos, de la nueva ley de inversión extranjera en septiembre de 1995; (b) la creación y extensión del uso del peso cubano "convertible", y la apertura y expansión de los lugares de cambio extranjero a finales de 1995 y en 1996 (a pesar de que estos lugares no venden dólares); (c) la legalización del mercado de pescado a principios de 1996; (d) la implementación, entre enero y diciembre de 1996, de varios impuestos menores exigidos en la ley de 1994 (ingresos personales en divisa fuerte incluyendo el auto empleo, excepto para los envíos, tasas para los pasajeros de los aeropuertos, ayudas comerciales y peajes de autopistas) y la creación de una Oficina para la Administración de Impuestos encargada del cobro de los impuestos; (e) nuevas regulaciones de autoempleo y expansión de las profesiones autorizadas, así como impuestos más altos en mayo de 1996; (f) la creación del Banco de Inversión y el Banco Metropolitano como corporaciones cubanas (sociedades anónimas) en 1996; (g) la autorización de zonas de libre comercio y parques industriales mediante un decreto de junio de 1996, que se espera se organice en cuatro ciudades de puerto, así como en el aeropuerto de la Habana (a pesar de que ninguna había empezado los trámites a finales de 1996); (h) la autorización en mayo de 1997 de alquilar casas a los extranjeros bajo fuertes restricciones y fuertes impuestos; y (i) la regulación en mayo de 1997 del Banco Nacional de Cuba y de instituciones financieras no bancarias (a pesar de que la esperada reforma bancaria no ha sido desarrollada todavía).

Los indicadores del estancamiento eran: (a)que no se produjo ni la eliminación de 500.000 a 800.000 trabajadores que no se necesitaban en el sector estatal, ni se retiraron todos los subsidios del estado a las empresas públicas (ambos diseñados para 1996 y no implementados entre 1996-1997); (b) las posposición de la implementación de los impuestos sobre trabajadores y la contribución de los trabajadores a la seguridad social (en octubre de 1997 Lage 
dijo que estaban esperando para unas "condiciones más adecuadas");(c) la significativa ralentización de la reducción del excedente monetario a principios de 1996 y el crecimiento durante el resto del año (como resultado de la no implementación de las medidas anteriores), así como un aumento de la emisión monetaria; (d) la exclusión de los graduados universitarios y de las actividades profesionales en la expansión de ocupaciones autorizadas de autoempleo; (e) el fallo de la ley de inversión externa de autorizar la contratación directa (como se esperaba), el pago y promoción de los trabajadores en empresas mixtas con inversión externa (estas actividades son todavía desarrolladas por la agencia estatal); (f) la no autorización a los residentes cubanos o a grupos de trabajadores de desarrollar negocios de pequeño y mediano tamaño (Lage señaló en abril de 1997 que tal medida sería pospuesta); (g) la afirmación oficial de que la convertibilidad del peso no tendría lugar a medio plazo sino que se pospondría hasta que la recuperación económica estuviera consolidada y una reserva extranjera acumulada (h) la falta de referencia alguna a la necesitada reforma comprehensiva de los precios.

Algunos importantes acontecimientos externos sucedieron en 1996 que afectaron adversamente a Cuba: la aprobación del Acta Helms-Burton (a pesar de que Clinton temporalmente suspendió el derecho a denunciar a los inversores extranjeros que "traficaran" con las propiedades americanas confiscadas; la elección ganada por Yeltsin para la presidencia de Rusia, derrotando al candidato comunista Zyuganov; la victoria del conservador José María Aznar como presidente del gobierno español derrotando a la coalición de izquierda que había dado apoyo a Cuba; la decisión de la Comunidad Europea de no proporcionar ayuda económica a Cuba debido al fracaso de la isla en su movimiento hacia la democracia. El 23 de marzo de 1996, el vicepresidente Raúl Castro advirtió en un discurso público que aquel año, 1990 y los sucesivos, serían "tensos" debido al Acta Helms-Burton y a otros reveses externos, por lo que hacía falta comprometerse en una batalla ideológico-política para controlar los efectos negativos de estos acontecimientos y evitar las divisiones internas.

En el mismo discuso, R. Castro criticó fuertemente los siguientes aspectos de la reforma económica, así como a las instituciones y académicos que la habían apoyado. El capital extranjero y las empresas unidas son una influencia perversa porque los trabajadores empleados en éstas pueden admirar su tecnología y pagar sus primas en dólares, y asî concluir que son mejores que las empresas del estado; estas actitudes pueden debilitar el nacionalismo, los sentimientos anticapitalistas de las masas. Además, algunas corporaciones extranjeras ofrecen comisiones y regalos a los funcionarios cubanos estimulando el soborno y la corrupción. Los turistas vienen de países capitalistas y promueven una ideología consumista, el resurgimiento de la prostitución, las actividades ilegales y las desigualdades; y los visitantes cubano-americanos son fuentes de penetración ideológica. La distribución de las parcelas de tierra en usufructo ha aumentado el número de agricultores privados que promueven el individualismo en lugar del socialismo, y esto ha conducido a la acumulación de largas sumas de dinero que son almacenadas, gastadas en bienes de consumos o invertidas en nuevos negocios privados. Algunos agricultores privados, así como empleados medios y una parte de los autoempleados se han enrolado en actividades ilegales uniéndose a una emergente capa de gente rica. El autoempleo tiene efectos negativos como el enriquecimiento basado en la existente escasez, la realización de nuevos y viejos crímenes, y la organización de grupos independientes del Estado que son receptivos al trabajo del enemigo. Los envíos del exterior de divisa fuerte han creado desigualdades, han facilitado la promoción del estilo de sociedad consumista norteamericano y han cambiado los valores de algunas personas, especialmente los de los jóvenes. Las ONGs son útiles para el estado pero, peligrosas por su independencia, por la recepción de donaciones extranjeras y por tener unas metas diferentes a las del gobierno; son susceptibles a la manipulación externa y a la infiltración. Algunas instituciones académicas (como el CEA) y determinados académicos han caído "en la tela de araña de los cubanólogos que sirven a los intereses norteamericanos y promueven una transición al capitalismo"; como resultado optan por "posiciones ambigüas o neutrales" y "evitan el enfrentamiento o los temas problemáticos” en los encuentros en el extranjero, mostrando así "una inaceptable debilidad frente a los opositores doblegándose a su postura”.

Para erradicar los problemas descritos y controlar los efectos negativos de la reforma, R. Castro pidió al partido: diseñar una política unificada exenta de toda debilidad, asegurar que el mercado está subordiando al plan y al estado, regular estrictamente las medidas de reforma, aumentar la supervisión del embriónico sector privado, prevenir e imponer duras sanciones a los que violen las reglas, y examinar muy de cerca esos centros académicos que se han covertido en "caballos troyanos" y "quintas columnas" para que "puedan jugar el rol que se les ha asignado" y no "adoptar actitudes pasivas y complacientes que les distraigan de las metas para las que el estado revolucionario fue creado".

El descrito efecto escalofriante de la reforma fue confirmado por el Congreso del Partido Comunista que tuvo lugar en octubre de 1997. Entre retroceder (una opción imposible) y continuar (como los reformistas puros recomendaban), el Partido optó por mantener el status quo, porque una mayor apertura de la economía y expansión del sector no estatal podría haber amenazado el poder del régimen. La Resolución Económica del Congreso incluía los siguientes puntos: (a) alababa a las UBPCs y las dejaba intactas, a pesar de la crítica de la opinión pública a éstas y la petición de Lage de que sus problemas tenían que ser solucionados; (b) afirmaba que la propiedad del estado continuaría siendo un elemento intrínseco del sistema socialista y se incrementó su eficiencia sobre otras formas de propiedad, como las cooperativas o el régimen privado; (c) las empresas que habían sido alabadas, gestionadas por las fuerzas armadas como un modelo a ser seguido por el resto de las empresas del estado; y (d) afirmaba que el mercado tendría su espacio pero, bajo la regulación estricta del gobierno que impediría beneficios injustificables resultantes de la apertura económica. En su discurso de despedida 
del Congreso, el presidente Castro dejó clara su oposición a cualquier tipo de privatización de las empresas del estado como los chinos habían hecho. Y el Secretario del Partido en La Habana declaró que Cuba no podía seguir el camino chino por las diferentes condiciones y efectos adversos que causaría en la arena social (Lage, 1997; Rohter, 1997).

\section{c) Una explicación de la paralización de la reforma y de las alternativas políticas potenciales}

En opinión del autor, los indicadores de estancamiento y retroceso de la reforma son más fuertes que las que sugieren progresos continuos. De hecho, el proceso de reforma parece haber sido detenido o ralentizado de forma significativa desde 1995. El discurso de Raúl Castro de 1996 y las acciones que le siguieron evidenciaron la intención del gobierno de reforzar el control de la reforma, y el Congreso del Partido de 1997 ha mantenido el status quo.
La paralización del declive económico en 1994, la modesta tasa de crecimiento de 1995 y la alta tasa de 1996 (a pesar de su cuestionable tamaño), combinado con la consecución de una cierta estabilidad financiera, hicieron probablemente que el Presidente Castro creyera que su régimen era seguro $y$, por tanto, que era conveniente paralizar el proceso de reforma con el fin de evitar el agravamiento de los problemas descritos más arriba y el riesgo de inestabilidad del régimen. La lógica política, consecuentemente, ha prevalecido sobre la lógica económica. Las oscuras perspectivas económicas para 1998 pueden conducir a dos políticas diferentes: seguir el curso actual pero ajustando el control político, o un tímido reempuje de la reforma económica con regulación estricta y control de los efectos "negativos". La perspectiva de un movimiento fuerte hacia el mercado, al igual que en China y Vietnam parecía nula a fines de 1997.

\title{
RESUMEN
}

En 1989, Cuba tenía la economía más colectivizada, igualitaria, dependiente del exterior y subvencionada soviéticamente, de todo el mundo socialista. El colapso de la URSS supuso una dura crisis económica en la isla en los años noventa y condujo a un proceso de reformas de mercado que se llevó a cabo de forma tímida y vacilante. Las series estadísticas se desvanecen a principios de la transición, haciendo las evaluaciones serias virtualmente imposibles. Entre 1995 y 1997 se han extraído datos importantes pero con una confianza cuestionable. Este artículo reúne y analiza todas las estadísticas disponibles al respecto con el fin de determinar la actuación socioeconómica de Cuba, centrándonos en cinco áreas cruciales: indicadores macroeconómicos, producción material, sector exterior, condiciones sociales, así como estado actual y perspectivas de la reforma.

Palabras claves: Cuba, reforma, indicadores macroeconómicos y sociales.

\begin{abstract}
In 1989, Cuba had the most collectivized, centralized, egalitarian, externally dependent and Soviet-subsidized economy within the socialist camp. The collapse of the latter prompted a severe economic crisis in the island in the 1990 s, forcing a process of market reform albeit timid and vacillating. Statistical series vanished at the beginnig of the transition, making a serious evaluation virtually impossible. In $1995-97$ important data were released but their reliability are questionable. This article assembles and analyzes all available pertinent statistics in order to asses Cuba's socio-economic perfomance in 1990-97, by focusing on five crucial areas: macroeconomic indicators, physical output, external sector, social conditions, and status and prospects of the reform.
\end{abstract}

Key Words: Cuba, Reform, Macroeconomic-Social Indicators. 